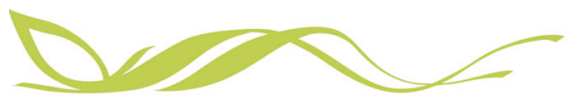

COMMUNICATIONS

ARTICLE

A) Check for updates

https://doi.org/10.1038/s43247-020-00077-4 OPEN

\title{
Contribution of climatic changes in mean and variability to monthly temperature and precipitation extremes
}

Karin van der Wiel (1) ${ }^{1 凶} \&$ Richard Bintanja ${ }^{1,2}$

The frequency of climate extremes will change in response to shifts in both mean climate and climate variability. These individual contributions, and thus the fundamental mechanisms behind changes in climate extremes, remain largely unknown. Here we apply the probability ratio concept in large-ensemble climate simulations to attribute changes in extreme events to either changes in mean climate or climate variability. We show that increased occurrence of monthly high-temperature events is governed by a warming mean climate. In contrast, future changes in monthly heavy-precipitation events depend to a considerable degree on trends in climate variability. Spatial variations are substantial however, highlighting the relevance of regional processes. The contributions of mean and variability to the probability ratio are largely independent of event threshold, magnitude of warming and climate model. Hence projections of temperature extremes are more robust than those of precipitation extremes, since the mean climate is better understood than climate variability.

\footnotetext{
${ }^{1}$ Royal Netherlands Meteorological Institute, De Bilt, The Netherlands. ${ }^{2}$ Energy and Sustainability Research Institute Groningen, Groningen University, Groningen, The Netherlands. ${ }^{凶}$ email: wiel@knmi.nl
} 
$\mathrm{V}$ ariability in weather and climate inherently leads to the occurrence of extreme weather or climate events. These events, more unusual and more severe than normal or average weather, include for example heatwaves (high-temperature events), cold waves (low-temperature events), downpours (heavy-precipitation events) and droughts (low-precipitation events). Societies and natural ecosystems are increasingly at risk of such extreme weather events ${ }^{1-4}$. For instance, heatwaves increase morbidity and mortality, reduce labour efficiency and crop yields, and intensify droughts and forest fires ${ }^{5,6}$, while downpours lead to floods that result in human casualties, damage to infrastructure, crop failure, landslides, and insurance $\operatorname{costs}^{7-9}$. Consequently there is a huge societal and scientific interest to quantify and understand future trends in the frequency and intensity of extreme events and their attribution to anthropogenic climate change $e^{2-4}$. Recent climate studies have contributed to quantifying such trends, but the climatic mechanisms behind changes in climate extremes often remain elusive. This is mainly because extreme event occurrence responds to both changes in mean climate and to changes in climate variability ${ }^{10-14}$. These two fundamental aspects of the climate system exhibit considerable changes in response to (human-induced) climate warming $^{11,14}$, but often not in the same manner.

Importantly, changes in mean and variability can generally be attributed to different climate mechanisms ${ }^{14-17}$, and, as a result, may have opposing effects on extreme event frequency. The combined effect on changes in regional extreme event occurrence thus depends on the balance between, and effectivity of, the associated driving mechanisms. For example, the Arctic region will experience increasing mean temperatures due to temperature and surface albedo feedbacks ${ }^{18-20}$, but sea ice retreat will ultimately lead to a reduction in temperature variability ${ }^{21,22}$. The individual contributions to the occurrence of hightemperature events are thus of opposite sign, the total effect of climate change on high-temperature event frequency therefore depends on the balance between the two mechanisms. Another example concerns Arctic precipitation, for which mean changes are driven mainly by sea ice retreat and surface evaporation ${ }^{23}$, whereas changes in variability are governed by atmospheric poleward moisture transport ${ }^{17}$. Even though both are projected to increase as a result of climate change, and thus contribute to more and more extreme heavy-precipitation events, the mechanisms behind enhanced Arctic downpours crucially depend on the relative importance of increases in mean precipitation and in precipitation variability. This attribution of changes in climate extremes to specific climate mechanisms is important because the drivers of changes in the mean climate are fairly well known, in contrast to those that govern changes in climate variability ${ }^{13}$. Unfortunately, the separation of mean changes and changes in variability with respect to their contribution to changing climate extremes is currently unknown.

Here we quantify what part of a change in extreme event probability is due to a shift in the mean climate, and what part due to a change in climate variability. We use the Probability Ratio (PR) concept ${ }^{24,25}$ in conjunction with large-ensemble climate modelling ${ }^{26}$ to provide robust estimates of the drivers of change in extreme events (see Methods). PR represents the changing probability of an extreme event caused by anthropogenic climate change. We extend the PR framework to split the conventional (or total) PR (which thus includes changes in both mean and variability), in a 'PRmean' representing changes in event probability due to a change in mean climate and a 'PRvar' for changes due to changes in climate variability (Fig. 1). We then apply several state-of-the-art large-ensemble global climate model simulations to realistically quantify the individual contributions of future changes in means and in variability to an altered extreme event occurrence. Evidently, PRtotal values and its partitioning into the contributions from changes in the mean and variability differ among climate variables and are also strongly dependent on the region of interest. As such, the novel split of PR into its mean and variability components will yield valuable insight into the regionally-dependent climate mechanisms that govern changes in extreme climate events.

\section{Results}

Attribution of global projections of changes in extreme event occurrence. Future changes in the probability of extreme monthly high-temperature and heavy-precipitation events exceeding the 98th percentile in the present-day climate will be substantial (Fig. 2). Using large-ensemble time slice simulations ${ }^{27}$ with the global climate model EC-Earth ${ }^{28}$ (see Methods), we find that extreme high-temperature events in a $2{ }^{\circ} \mathrm{C}$ warmer climate will increase virtually everywhere (Fig. 2a) ${ }^{1,24}$. The largest PR-values are located over the tropical oceans, with values exceeding 20 in many locations (indicating that the chance of exceeding a high-temperature threshold will be 20 times more likely in the future than today). This can be attributed to the relatively narrow distribution of near-surface temperatures over ocean surfaces, meaning that a small shift of the mean will move a substantial part of the distribution over the extreme event threshold. In contrast, the average PRtotal over global land areas is more modest (5.5). By far the largest contributor to the increase in extreme heat probability is the mean warming (PRmean averaged over global land (a) Climate simulations

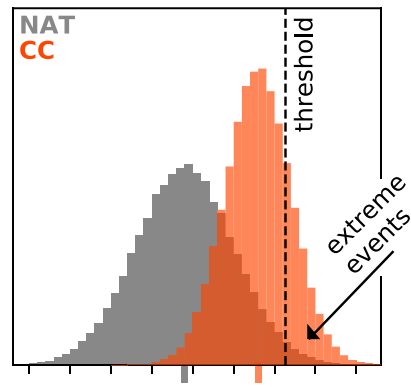

(b) Remove change in mean

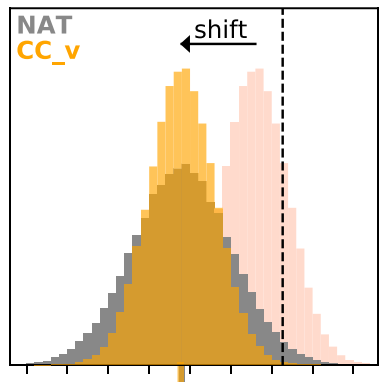

(c) PR components

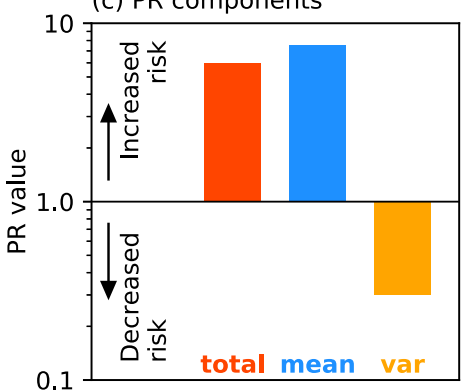

(d) Contributions

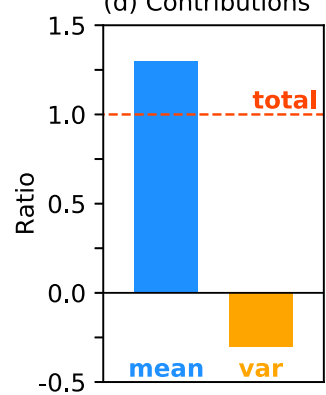

Fig. 1 Schematic diagram of the breakdown of the Probability Ratio (PR) in the individual contributions of changes in the mean state and changes in climate variability to the total change in extreme event probability (see Methods for details). a Two simulated distributions of some climate variable ('NAT' and 'CC'), the PRtotal value is computed from the number of events exceeding the threshold in both distributions (Eq. (1)). $\mathbf{b}$ The effect of change in mean climate is removed by shifting the 'CC' distribution such that it has the same mean value as the 'NAT' distribution, PRvar can then be evaluated based on threshold exceedance in 'CC_v'. c PRmean follows from the PR-relationship (Eq. (2)), the individual contributions to PRtotal are found. $\mathbf{d}$ The ratio of contribution is determined from the different PR-values (Eq. (3)), and sum up to a total of 1. 
(a) Monthly high-temperature events, p98, 2C scenario

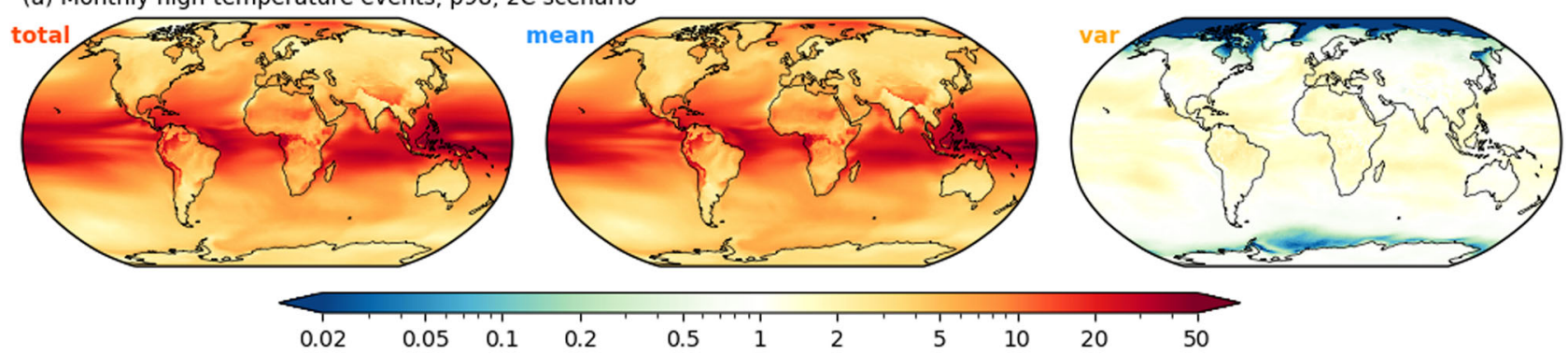

(b) Monthly heavy-precipitation events, p98, 2C scenario

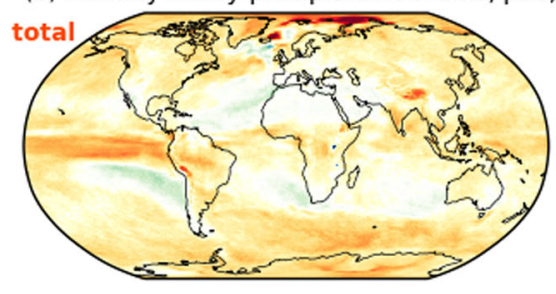

0.2
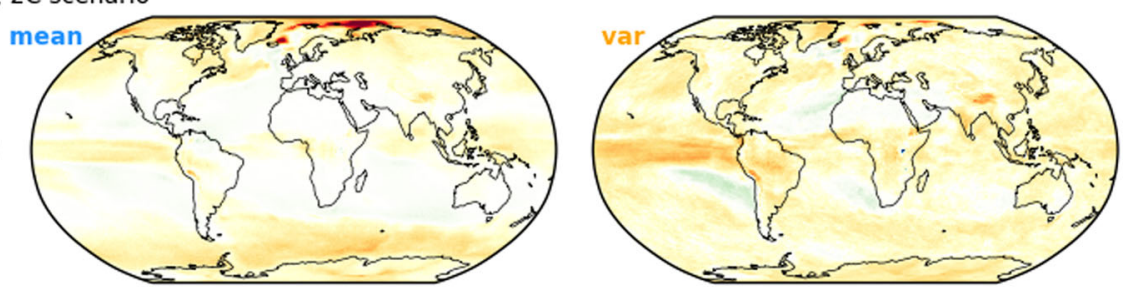

0.5

1

2

5

Fig. 2 Maps of the Probability Ratio (PR) for monthly extreme events exceeding the 98th percentile in a 2C-warming scenario (as specified in the Paris agreement) relative to the present-day climate. For a high-temperature events and $\mathbf{b}$ heavy-precipitation events; shown are from left-to-right the total PR, PR due to the change in mean climate and PR due to the change in climate variability.

(a) Monthly high-temperature events, p98, 3C scenario
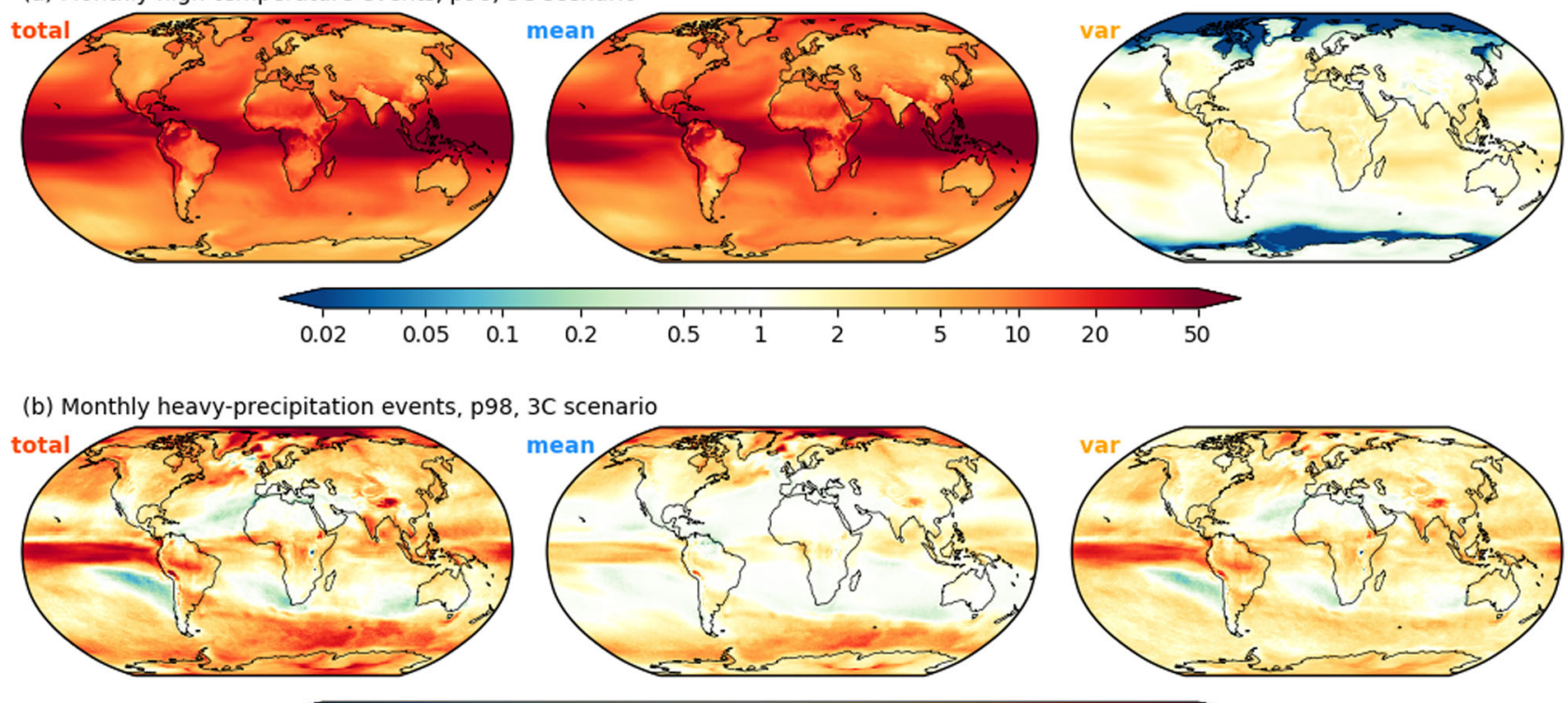

$0.2 \quad 0.5 \quad 1$

2

$5 \quad 10$

20

50

(b) Monthly heavy-precipitation events, p98, 3C scenario

0.2

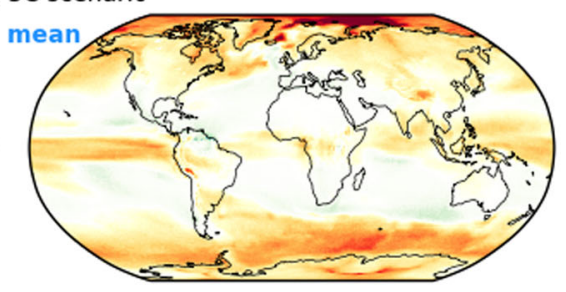

2

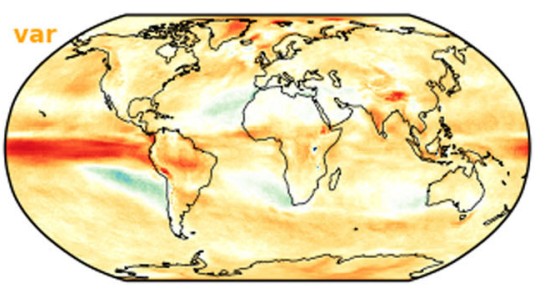

5

Fig. 3 As Fig. 2, but here for a 3C-warming scenario. Maps of the Probability Ratio (PR) for monthly extreme events exceeding the 98th percentile in a 3C-warming scenario relative to the present-day climate. For a high-temperature events and $\mathbf{b}$ heavy-precipitation events; shown are from left-to-right the total PR, PR due to the change in mean climate and PR due to the change in climate variability.

areas: 5.4), whereas changes in temperature variability only increases the event probability in a few tropical and midlatitude regions (PRvar averaged over global land areas: 1.1). This finding is in agreement scientific literature on processes governing changes in heat waves $^{29-32}$. Interestingly, subdued temperature variability in the polar regions related to sea ice retreat ${ }^{11,21,22,33}$ actually reduces the total increase in extreme heat occurrence.

Over $85 \%$ of the Earth's surface will see an increase of extreme heavy-precipitation events ${ }^{1,24}$, with an average PRtotal of 1.3 over continental regions (Fig. 2b). In contrast to high-temperature events, changes in precipitation variability ${ }^{14,21}$ contribute considerably to the increases in event frequency (average over global land areas: PRmean $=1.1$, PRvar $=1.2$ ). This suggests that, generally, one needs to incorporate both components and their underlying causes to fully understand and quantify the projected changes in heavy-precipitation events. This is a direct consequence of precipitation variability generally increasing more rapidly than mean precipitation for a variety of reasons, such as changing atmospheric moisture content, transport and dynamics, and changes in the intensity and spatial extent of atmospheric convection ${ }^{14,15,17,34}$. 
(a) Monthly high-temperature events, $\mathrm{p98}, 2 \mathrm{C}$ scenario

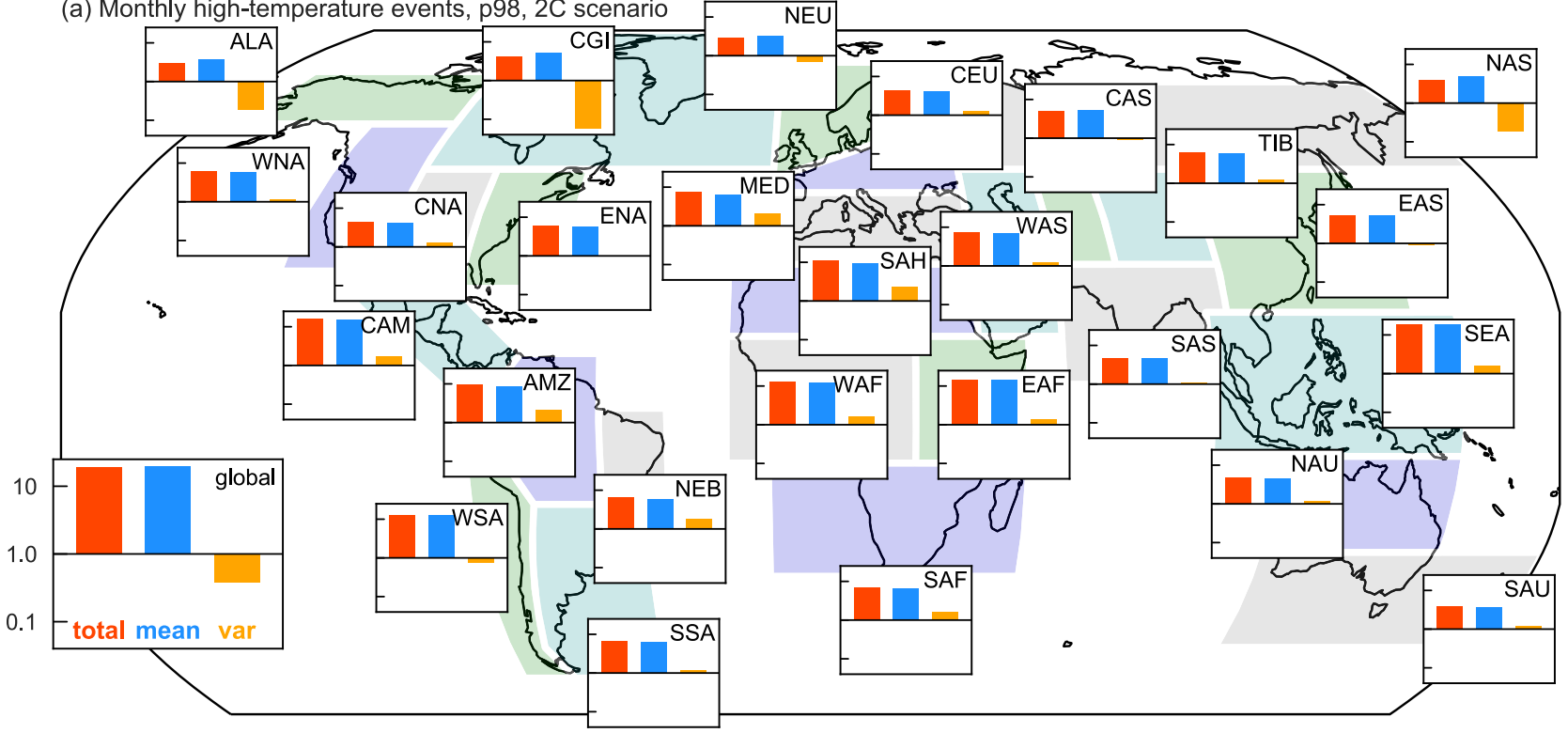

(b) Monthly heavy-precipitation events, p98, 2C scenario

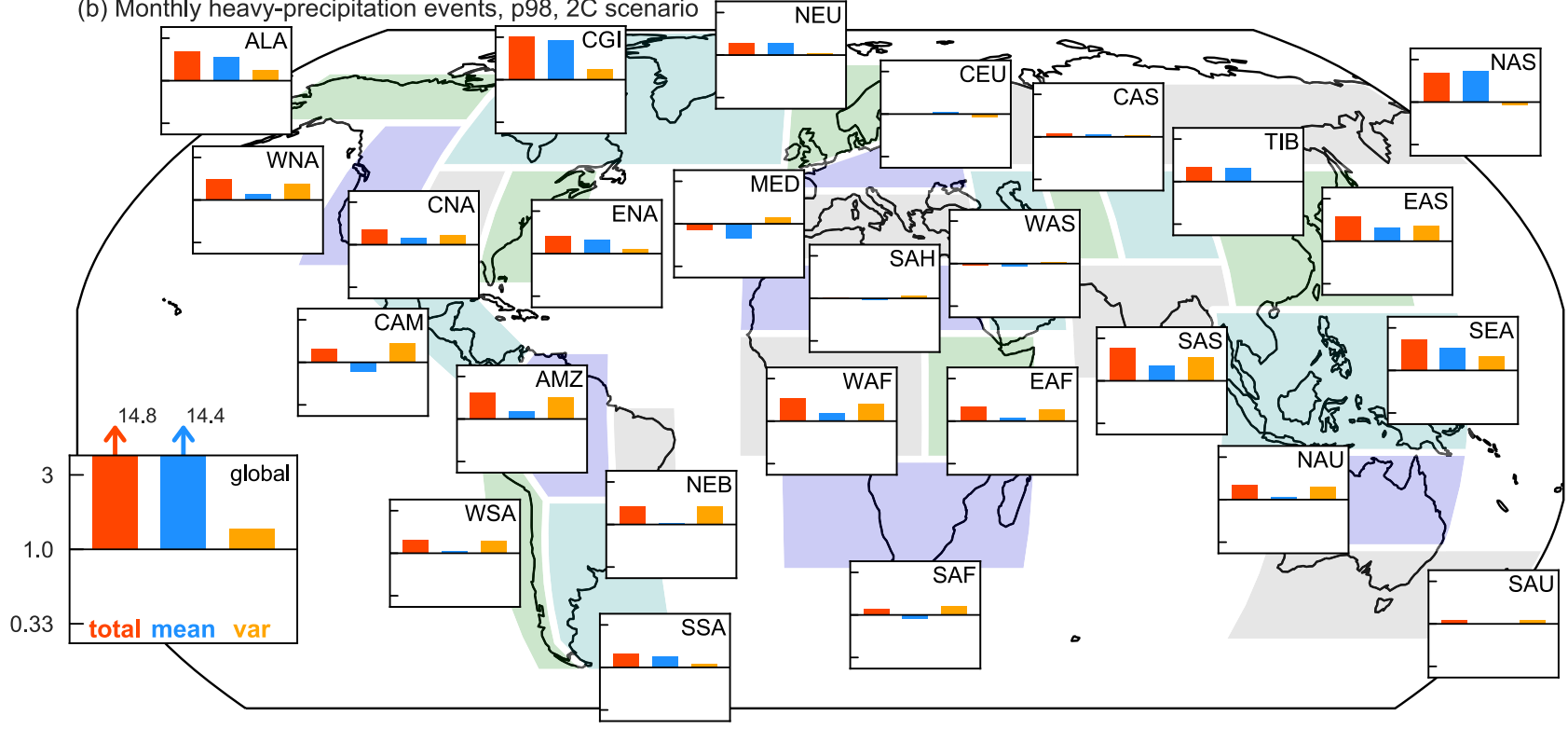

Fig. 4 The Probability Ratio (PR) for SREX regions (land only) and the global mean (land and ocean) for monthly extreme events exceeding the 98th percentile in a 2C-warming scenario (as specified in the Paris agreement) relative to the present-day climate. For a high-temperature events, $\mathbf{b}$ heavyprecipitation events. Red bars show the total PR, blue bars the PR due to the changes in mean climate and yellow bars the PR related to changes in climate variability. Values of the vertical axis are shown in the global subplot.

In a world with $3^{\circ} \mathrm{C}$ global temperature rise the various values of PR are higher than in a $2^{\circ} \mathrm{C}$ warmer world (Fig. 3), indicating that changes in extreme events are larger for greater magnitudes of global warming ${ }^{35-37}$. In contrast, the spatial patterns of PRtotal, PRmean and PRvar are qualitatively similar between the $2{ }^{\circ} \mathrm{C}$ and $3^{\circ}$ warming experiments (spatial correlations between 0.92 and 0.95 ), this indicates that the contributions of the associated climate mechanisms to the change in extreme events are largely independent of the magnitude of the climate forcing or response.

Regional climate processes governing changing extreme events. The strong spatial variations in PR-values and mean and variability contributions suggest that the climate mechanisms governing changes in climate extremes differ considerably from one region to the next. To quantify the individual contributions of mean and variability changes at the regional level, we evaluate
PR-values for each of the SREX regions (region boundaries and name abbreviations taken from IPCC SREX ${ }^{1,38}$ ). Regions close to the Arctic, most notably ALA, CGI, and NAS, are projected to experience a substantial increase in extreme heat probability, despite a considerable sea-ice related decrease in temperature variability ${ }^{21,22}$ that limits PRtotal (Fig. 4a). In contrast, changes in extreme heavy-precipitation events in these near-Arctic regions are much less affected by increasing precipitation variability ${ }^{17}$ (Fig. 4b), showing the importance of understanding the effectivity of these changes to extreme event occurrence. In relatively warm regions, such as CAM, NEB and SAU, the increase in likelihood of high-temperature events is dominated by the changes in mean temperatures (presumably because the overall greenhouse warming dominates local processes ${ }^{39}$ that amplify heat waves), whereas the increase of heavy-precipitation events is governed by the effects of increasing precipitation variability. This could imply 
(a) Monthly high-temperature events, p98

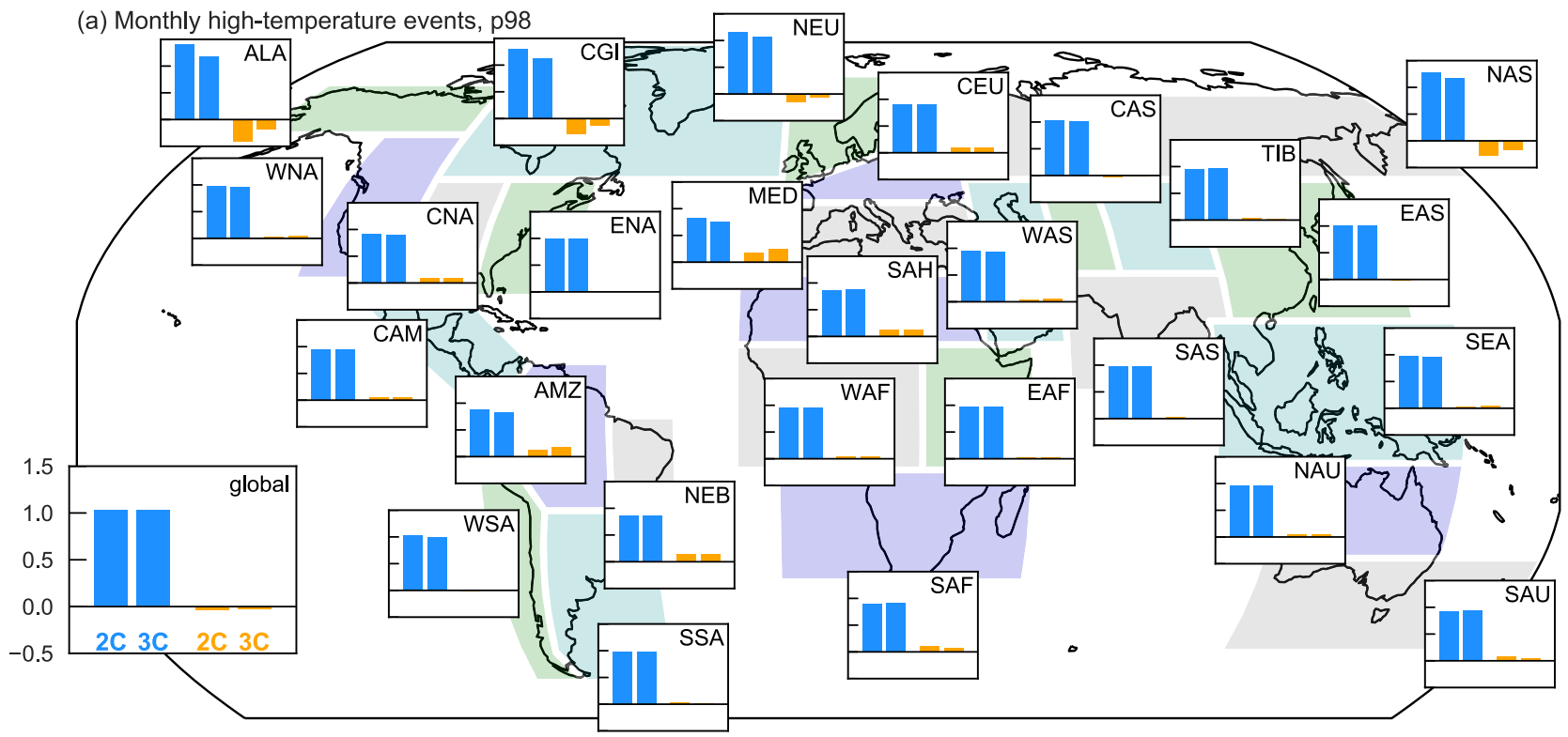

(b) Monthly heavy-precipitation events, p98

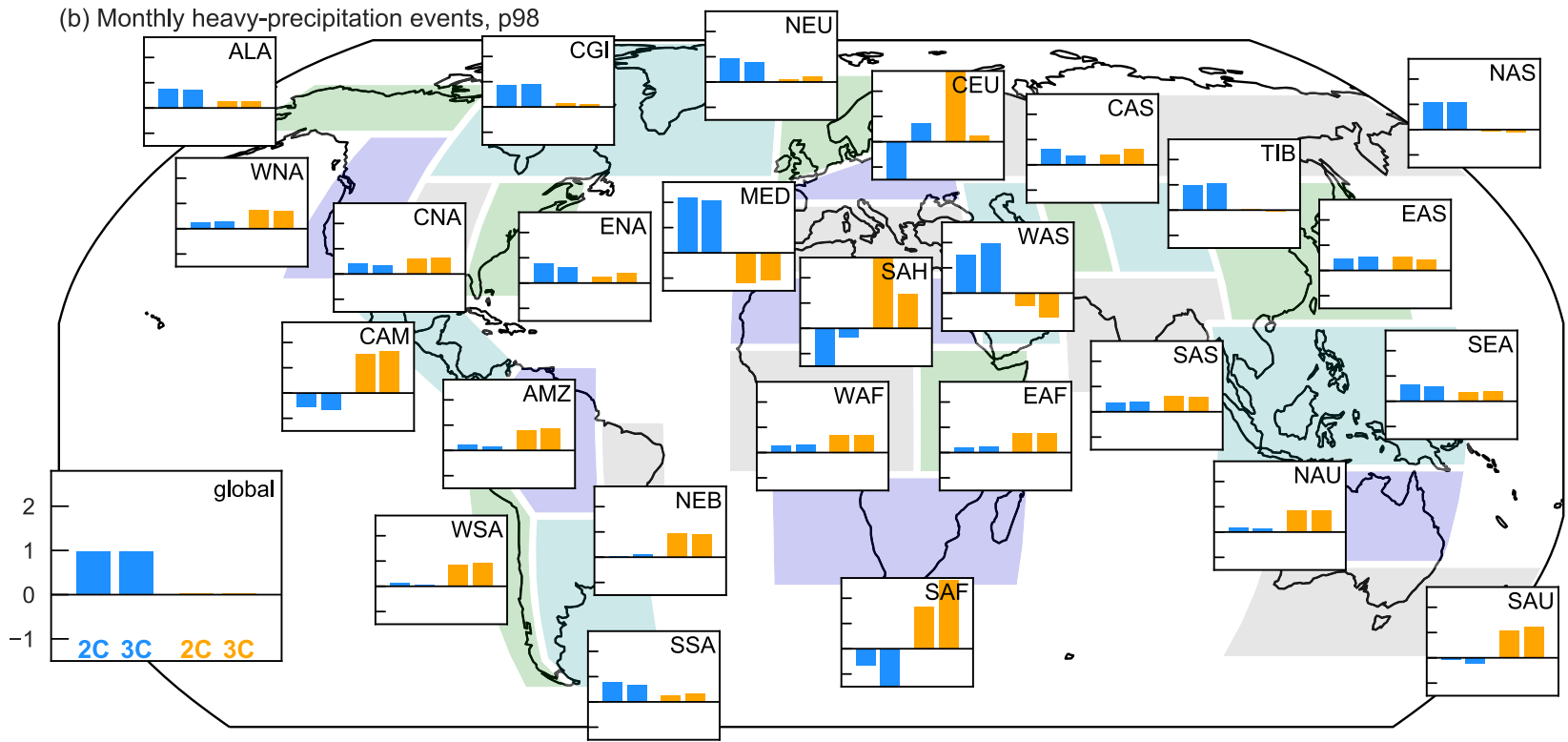

Fig. 5 The ratio of contribution of PRmean (blue bars) and PRvar (yellow bars) to PRtotal in a 2C- and 3C-warming scenario (left and right bar respectively) for events exceeding the 98th percentile for SREX regions and the global mean. For a monthly high-temperature events, $\mathbf{b}$ monthly heavy-precipitation events. Values of the vertical axis are shown in the global subplot.

that precipitation variability is primarily linked to mean warming via atmospheric convective processes ${ }^{15,34}$ through which precipitation extremes increase at a far greater rate than mean precipitation.

The relative contributions of changes in the mean and changes in variability can be quantified using the ratio of the respective contributions (Fig. 1d, Eq. (3)), and vary between regions and climate variables, dependent on regional mechanisms that govern changes in the mean and in variability. For example, in the nearArctic regions, the contribution of changes in the mean state to the increase of extreme high-temperature events is approximately 1.25 , indicating that reductions in temperature variability oppose the overall increase in PRtotal by 0.25 (Fig. 5a). The two contributions are closer to being equal for increasing heavyprecipitation events along the North American west coast (WNA) (mean: 0.25 , variability: 0.75 , Fig. $5 b$ ), where projected changes in the dynamics of atmospheric rivers impact both mean precipitation and precipitation variability ${ }^{40}$. Generally, these ratios are invariant for different levels of warming and also for extreme event threshold (Figs. 5 and 6), providing further evidence that the regionally-dependent climate mechanisms that govern trends in mean and variability, both causing changes in extreme events, are mostly independent of the magnitude of climate change, and of the extremeness of the event.

Intermodel comparison of contributing climate mechanisms. Climate models exhibit considerable intermodel differences, especially in terms of (regional) variability and extremes (and changes therein), since these are largely dependent on parameterised small-scale processes (e.g., soil moisture processes, surface heat fluxes, clouds, atmospheric convection ${ }^{1,41}$ ). To infer whether our findings are model-dependent we employ the largeensemble simulations collated by the US CLIVAR working group on Large Ensembles ${ }^{26}$ (see Methods) to investigate the 
(a) Monthly high-temperature events, $2 \mathrm{C}$ scenario

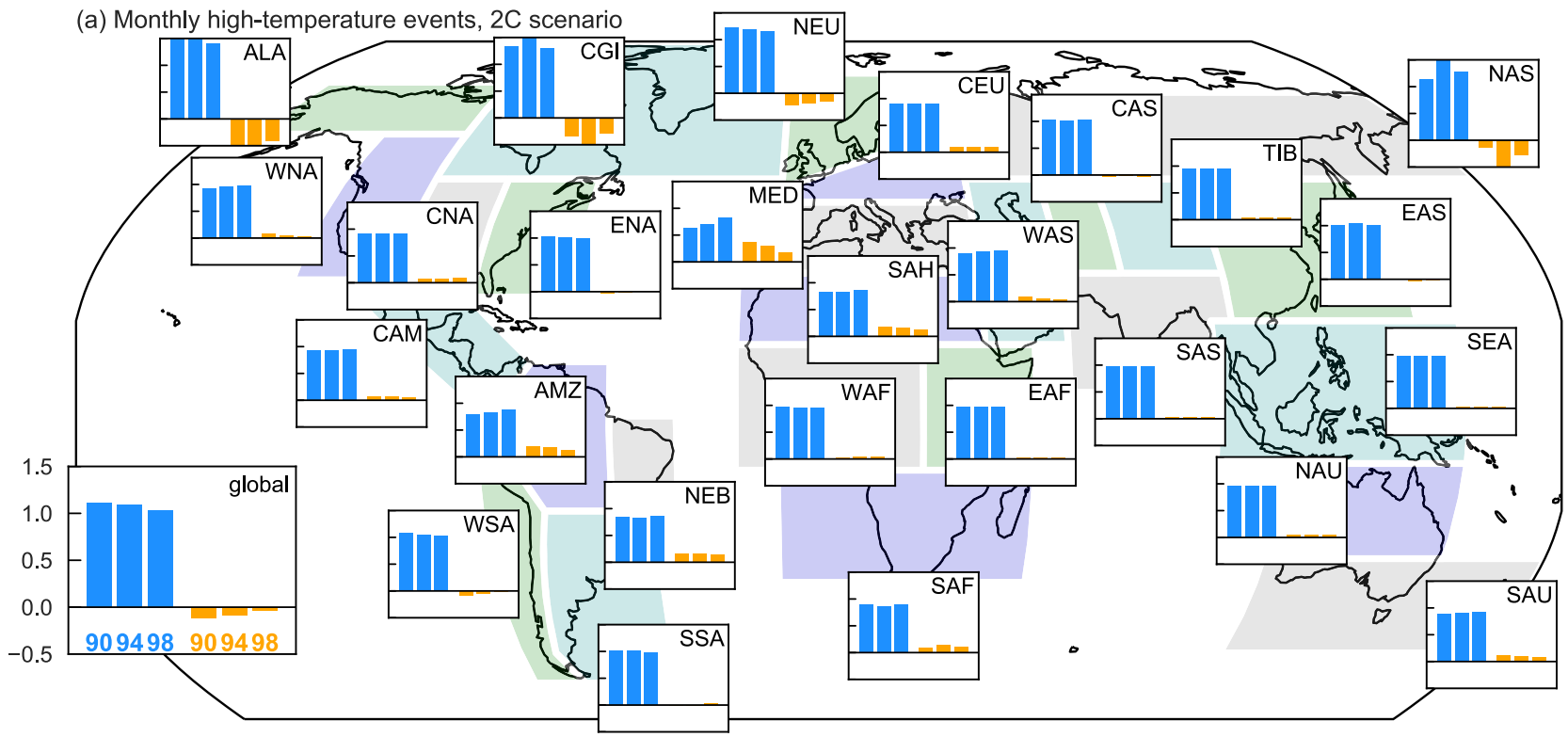

(b) Monthly heavy-precipitation events, $2 \mathrm{C}$ scenario

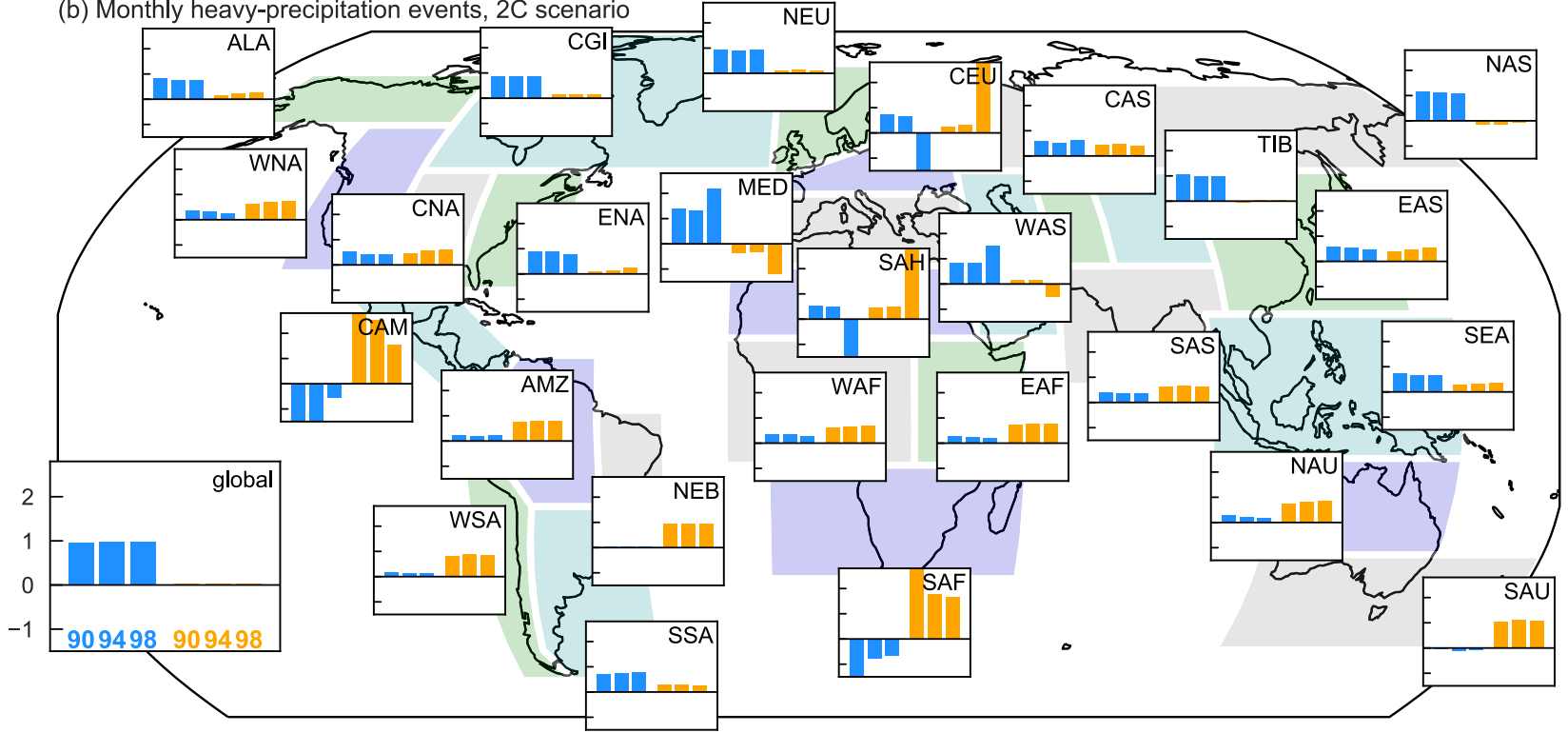

Fig. 6 The ratio of contribution of PRmean (blue bars) and PRvar (yellow bars) to PRtotal for events of exceeding different thresholds (bars, from left to right: 90th, 94th and 98th percentiles) in a 2C-warming scenario for SREX regions and the global mean. For a monthly high-temperature events, b monthly heavy-precipitation events. Values of the vertical axis are shown in the global subplot.

mechanisms behind changes in extreme event likelihood over time in a multi-model framework. Using transient scenario simulations covering the period 1950-2100 based on six global climate models we find that climate models agree on the sign of the change of the two contributors in the majority of the SREX regions. This model agreement is larger for high-temperature events than for heavy-precipitation events and is higher for the contribution of changes in the mean than for changes in variability (Fig. 7). There is some intermodel uncertainty in the magnitude of the changes, i.e. the exact PR-values.

Despite such intermodel differences, the ratio of the contributions of mean and variability to the change in extreme events is remarkably similar between models in most regions (Fig. 8). Evidently, changes in high-temperature events are, in all regions and in all models, governed by changes in the mean state (average contribution to PRtotal of 0.94). In contrast, projections of changes in heavy-precipitation events are less robust, mainly due to large spatial variability in extreme precipitation mechanisms, and also because the sign of total change, PRtotal above or below 1 , exhibits considerable intermodel differences. We will demonstrate model-dependencies by highlighting projections of temperature and precipitation extremes in two contrasting regions: the Mediterranean (MED) and Alaska (ALA) (Fig. 9). Projections of change in high-temperature extremes are well-defined in both ALA and MED (Fig. 9a, c), all models agree on the direction of change and the contributions of mean and variability, despite obvious regional differences. Note that the ratio of contribution is constant in time (not shown in a graph), indicating that the regional attribution of change to mean and/or variability does not depend on the magnitude of climate warming.

End of century PRtotal estimates for heavy-precipitation events in the MED range from 0.2 to 1.1 between models (Fig. 9d). This intermodel uncertainty for precipitation extremes, even in the direction of the change, can be attributed to the uncertain balance between two robust climate processes: a negative contribution of mean drying climate ${ }^{42}$ (PRmean between 0 and 0.4 ) and a 
(a) Monthly high-temperature events, p98, EOC RCP8.5

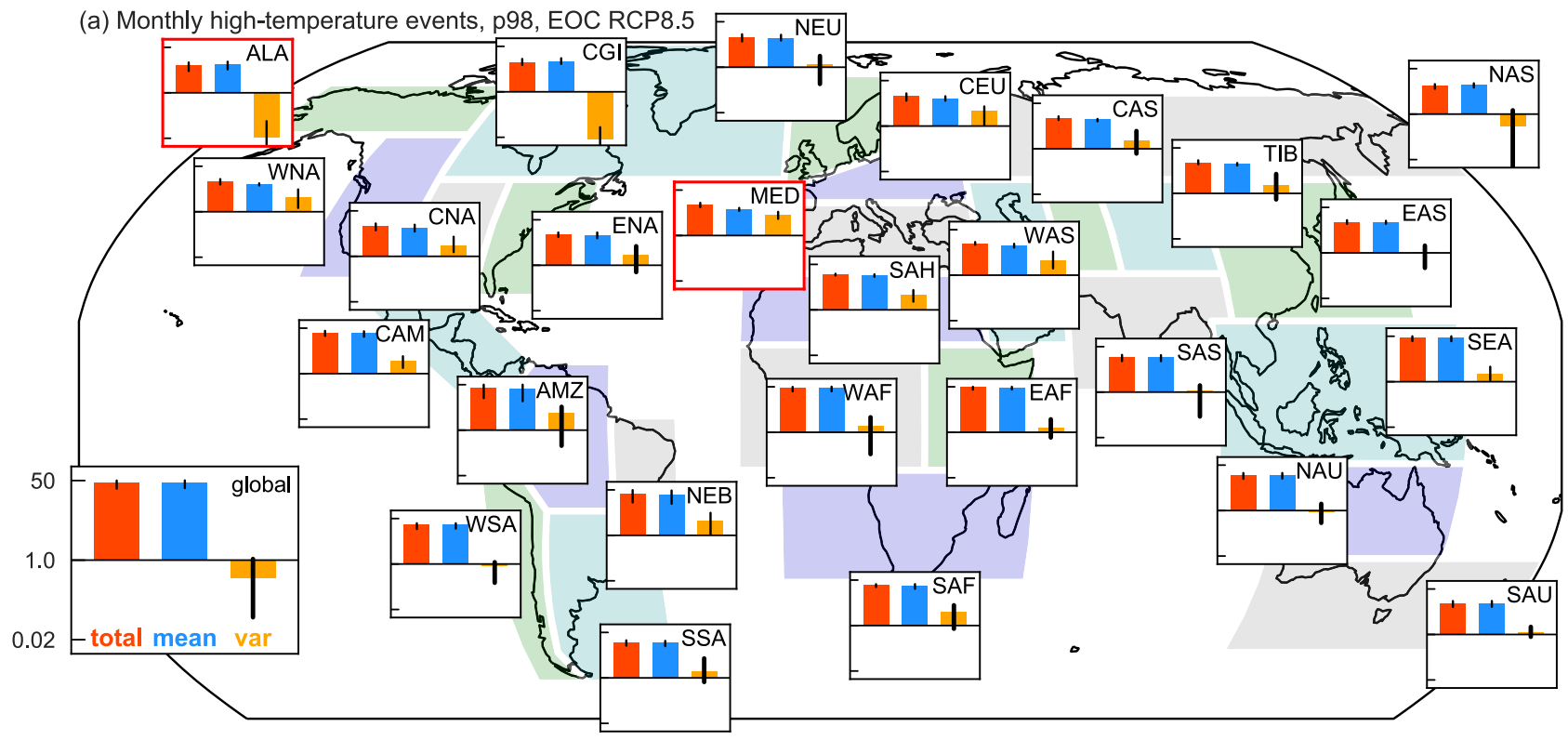

(b) Monthly heavy-precipitation events, p98, EOC RCP8.5 NEU

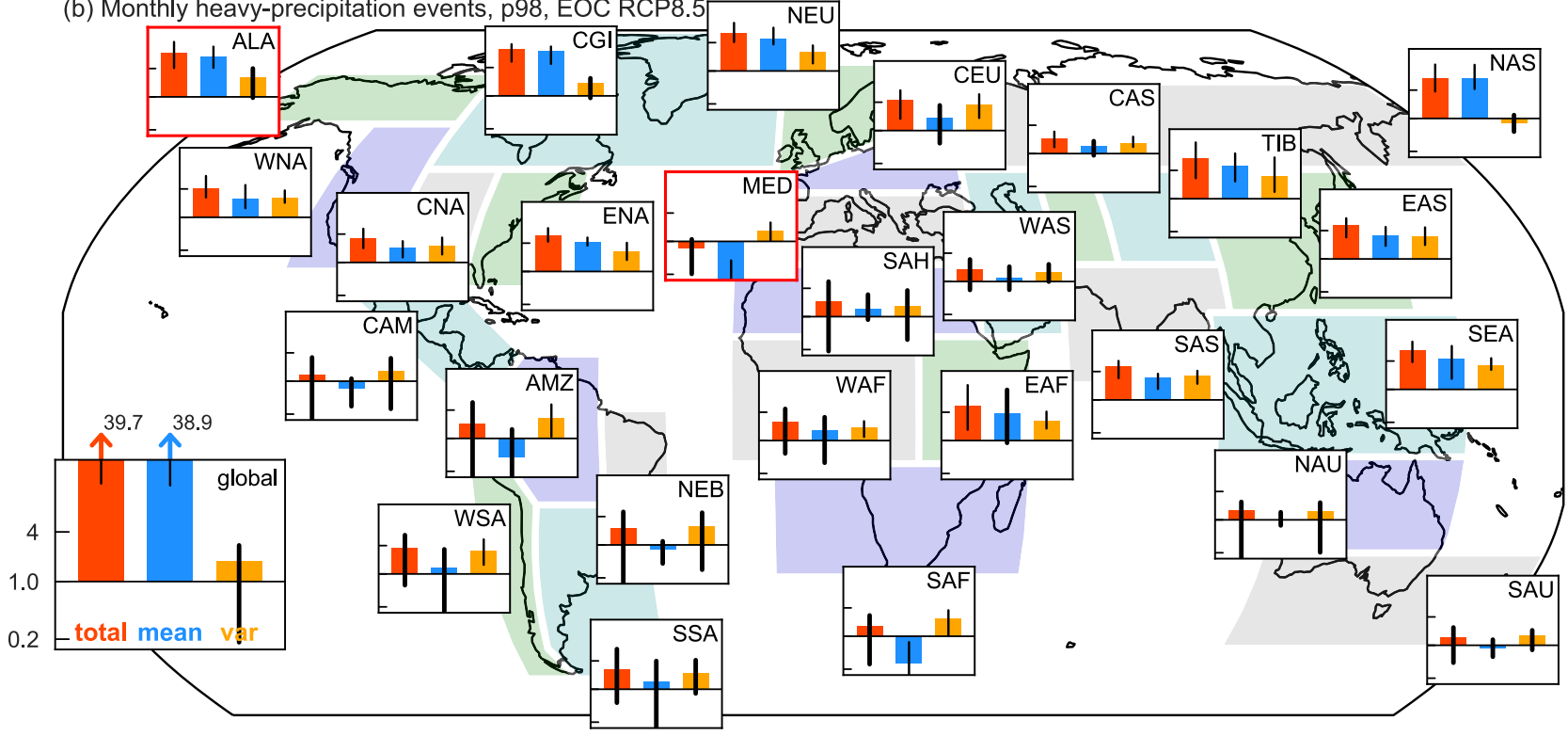

Fig. 7 As Fig. 4, but here based on the US CLIVAR multi-model large ensemble. Shown are PR values for the end-of-century (EOC, 2070-2099) relative to 1950-1979 under the RCP8.5 emission scenario. Coloured bars show the multi-model-mean (models included: CanESM2, CESM1, CSIROMk3.6, EC-Earth, GFDL-CM3, GFDL-ESM2M), vertical black lines indicate the inter-model range of the PR-values, lines are plotted thicker if there is intermodel disagreement in the sign of change. For a high-temperature events, $\mathbf{b}$ heavy-precipitation events. Red bars show the total PR, blue bars the PR due to the changes in mean climate and yellow bars the PR related to changes in climate variability. Values of the vertical axis are shown in the global subplot. The two highlighted regions are investigated in more depth in Fig. 9.

positive contribution due to increasing precipitation variability ${ }^{43}$ (PRvar between 1.0 and 2.5). Both trends are linked to changes in Mediterranean cyclones; models project a decrease in the number of Mediterranean cyclones (the dominant source of precipitation) owing to changes in circulation and storminess, but rainfall intensity in individual cyclones is projected to increase due to higher atmospheric moisture content ${ }^{44}$. In this region $80 \%$ of inter-model variance in the mean trend is due to uncertainty in the circulation response ${ }^{45}$, highlighting the need for improved understanding of physical processes and their (relative) importance in contributing to regional climatic changes. In Alaska the two processes work in the same direction and as a result PRtotal is better constrained (Fig. 9b).

\section{Conclusions}

In this study we attribute changes in extreme event occurrence to either climatic changes in mean climate or climatic changes in climate variability. By means of an extension of the PR framework, we are able to quantify the separate contributions. It is shown that future changes in monthly high-temperature extremes are mostly driven by increasing mean temperatures (on average $94 \%$ of the total), whereas changes in monthly high-precipitation events depend also considerably on changes in precipitation variability. Overall, climate models agree to a large degree on these drivers of change. The trend in extreme events varies between climate variables and regions, which is due to differences in climate mechanisms causing changes in the mean and in variability. 
(a) Monthly high-temperature events, p98, EOC RCP8.5

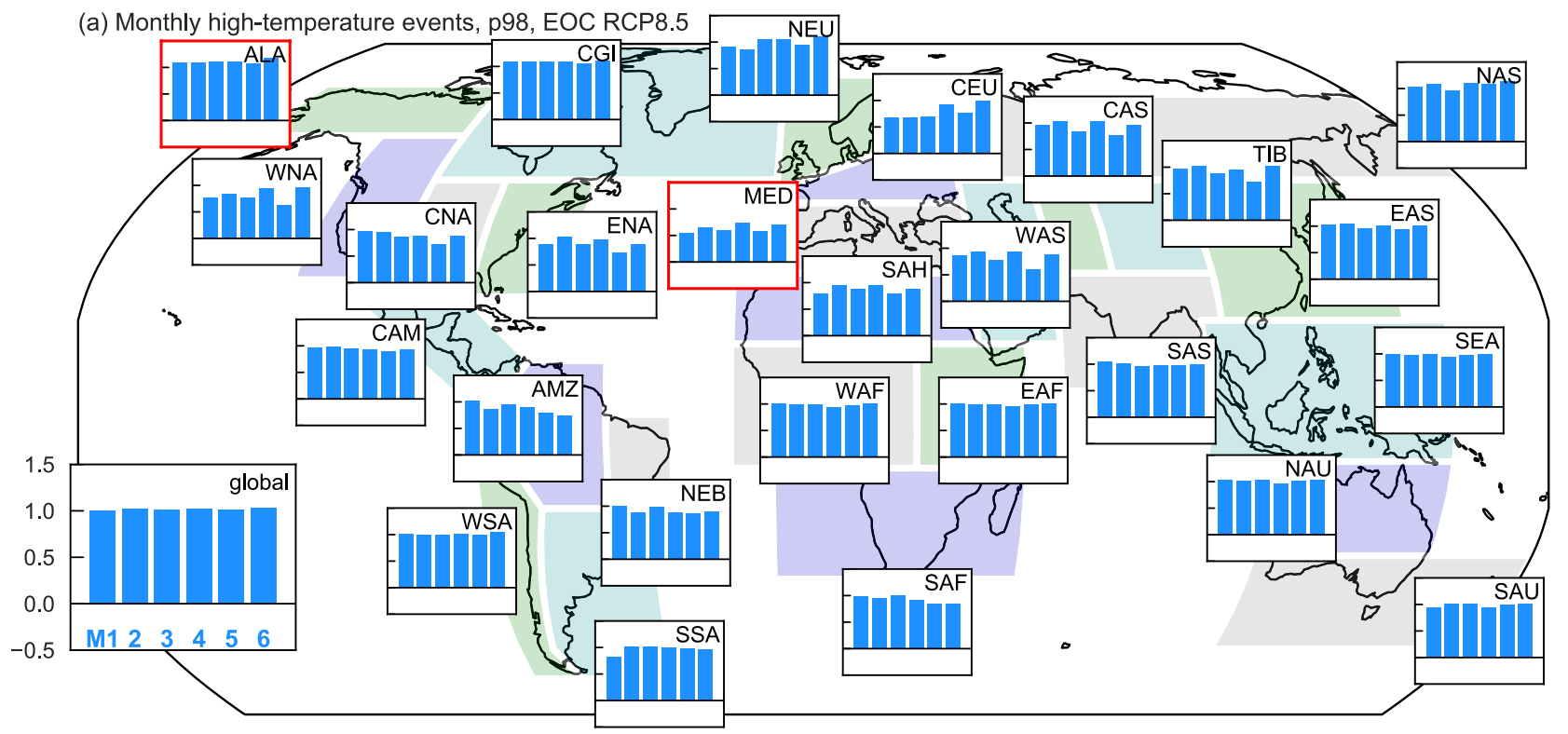

(b) Monthly heavy-precipitation events, p98, EOC RCP8.5 NEU

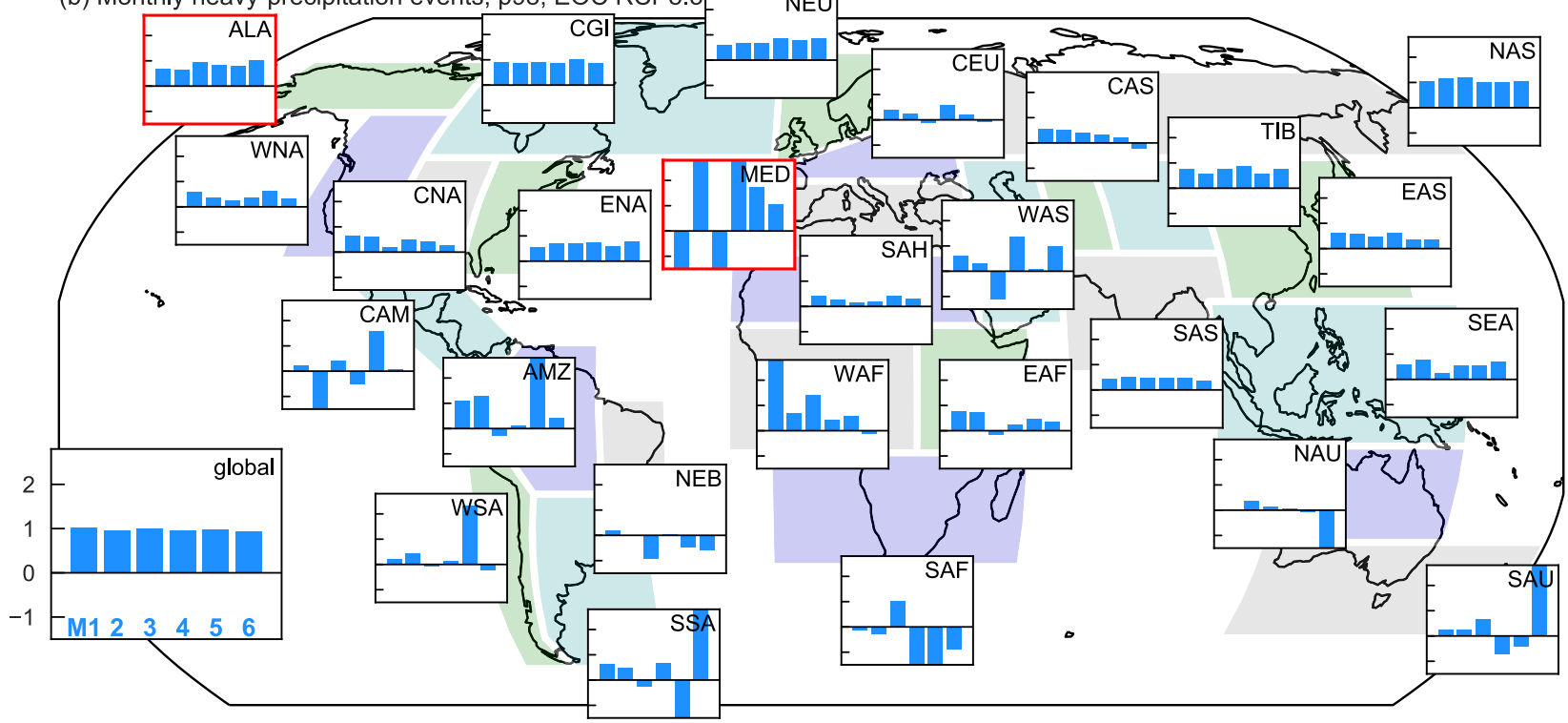

Fig. 8 The ratio of contribution of PRmean to PRtotal for extreme events based on the US CLIVAR multi-model large ensemble at the end-of-century (EOC, 2070-2099) relative to 1950-1979 under the RCP8.5 emission scenario. For a monthly high-temperature events, b monthly heavy-precipitation events. Models included: CanESM2, CESM1, CSIRO-Mk3.6, ECEarth, GFDL-CM3, GFDL-ESM2M (M1-M6 respectively). The two highlighted regions are investigated in more depth in Fig. 9. Values of the vertical axis are shown in the global subplot.

The breakdown into contributions of changing mean climate and changing climate variability is robust to varying definitions of the extremeness of the event (the event threshold), to the magnitude of future climate change (the level of warming) and to the choice of climate model. This insight is vital for assessing the robustness of projected changes in extreme event frequency. Our understanding of the associated mechanisms associated with changes in the mean climate is generally much better than those for changes in climate variability ${ }^{13}$. This suggests that considerable progress can be made by improving understanding of (trends in) climate variability, which in many regions depend on small scale climate processes (e.g. atmospheric convection, surface heat fluxes) that are normally parameterised in climate models ${ }^{1,41}$. The breakdown of trends in extreme events into the two basic contributors (mean, variability) provides valuable insights regarding the relative importance of climate processes governing these trends. This will help direct future research, as in many regions trends in climate variability remain unquantified and poorly understood.

\section{Methods}

PR framework. Conventionally, the Probability Ratio (PR $)^{24,25}$ is computed using data from two climate model simulations, one for a natural climate ('NAT') and one for a climate under human influence ('CC', Fig. 1a). PR is then defined as the ratio of event probabilities:

$$
\mathrm{PR}=\frac{\mathrm{P}_{\mathrm{CC}}}{\mathrm{P}_{\mathrm{NAT}}},
$$

with $\mathrm{PR}=1$ indicating no attributable change in extreme event probability, $\mathrm{PR}>1$ indicating an increase in event probability, and $\mathrm{PR}<1$ a decrease in event probability.

Here we extend the PR framework concerning changes in extreme event probability by separating this PR-value ('PRtotal') into a contribution from changes in the mean climate ('PRmean') and a contribution from changes in climate variability ('PRvar'). We define the mean climate as the annual mean value of the meteorological variable of interest, and climate variability as the variation of this 
(a) Monthly high-temperature events, p98, RCP8.5 ALA

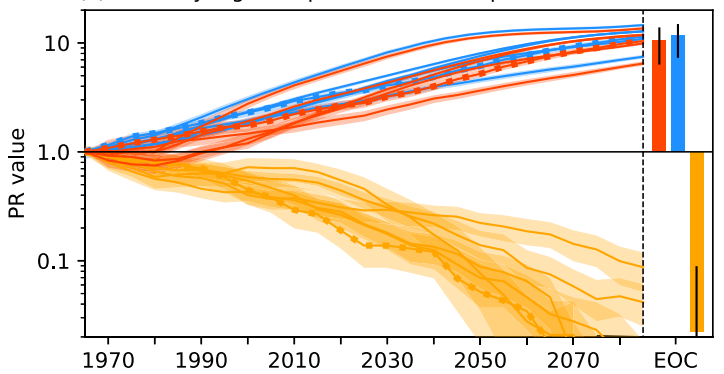

(c) Monthly high-temperature events, p98, RCP8.5 MED

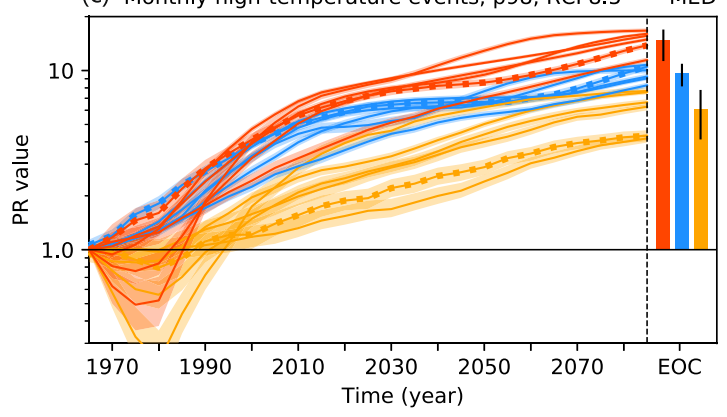

(b) Monthly heavy-precipitation events, p98, RCP8.5 ALA

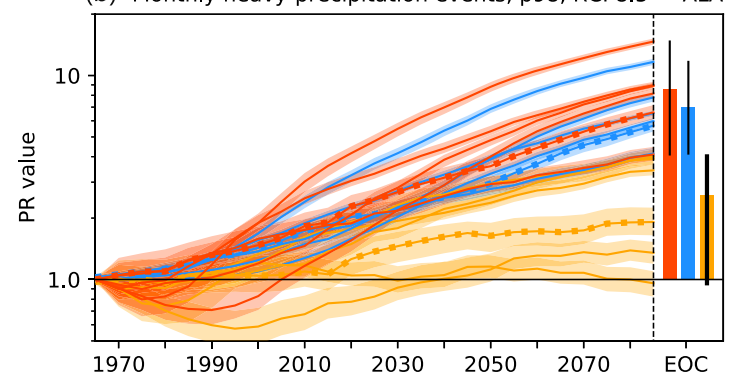

(d) Monthly heavy-precipitation events, p98, RCP8.5 MED

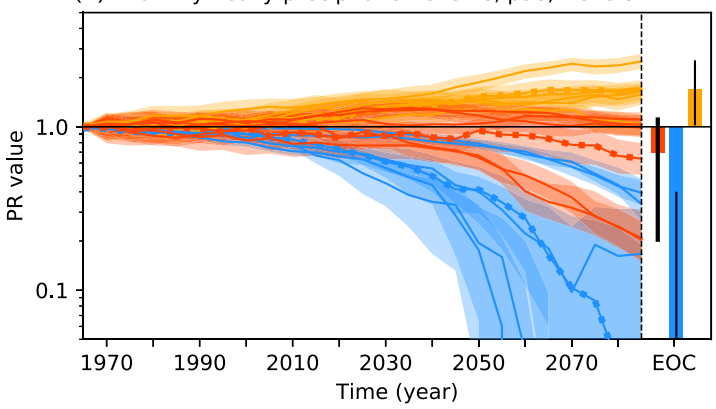

Fig. 9 Time series of the Probability Ratio (PR) for two SREX regions highlighted with a red box in Figs. 7 and 8 (ALA, MED), for monthly extreme events exceeding the 98th percentile under the RCP8.5 emission scenario relative to 1950-1979. For each of the six models we show the a, $\mathbf{c}$ hightemperature events, b, $\mathbf{d}$ heavy-precipitation events, and $\mathbf{a}, \mathbf{b}$ SREX region Alaska, c, d SREX region Mediterranean. Red lines show the total PR, blue lines the PR due to the changes in mean climate and yellow lines the PR related to changes in climate variability, with the $90 \%$ confidence interval shown in coloured shading. The EC-Earth model (used for Figs. 2 to 6 ) is highlighted with additional dots. Bars at the right of the plots show the end-of-century (EOC, 2070-2099) multimodel mean PR-values, with black vertical lines indicating the inter-model range, plotted thicker if there is intermodel disagreement in the sign of change.

variable around the climatic mean. Based on two climate datasets (e.g. 'NAT' and 'CC'), we compute the change in climatic mean. We then subtract the change in the mean from the CC dataset to create a new dataset 'CC_v' (Fig. 1b). The remaining difference between CC_v and NAT can then be attributed to trends in climate variability, from which PRvar is calculated. Following these steps, PRmean can be computed from the following relationship:

$$
\text { PRtotal }=\text { PRmean }+ \text { PRvar }-1 .
$$

In this equation, subtracting by 1 is necessary, since the reference PR-value is 1 , indicating no change in probability. PR-values should be interpreted on a logarithmic scale, with $\mathrm{PR}=2$ and $\mathrm{PR}=0.5$ representing a similar magnitude of change but in opposite directions (Fig. 1c).

To quantify the relative contribution of changes in the mean climate (PRmean) and changes in climate variability (PRvar) to the total change in extreme event probability (PRtotal), we evaluate the ratio of the contributions as follows:

$$
\text { Rmean }=(\text { PRmean }-1) /(\text { PRtotal }-1),
$$

and equivalently for Rvar (Fig. 1d). The two relative contributions (Rmean and Rvar) sum up to a total of 1 .

Data and analysis. To evaluate total PR and its components we use data from various large ensemble climate model simulations. We use a set of three time slice simulations using the state-of-the-art global climate model EC-Earth ${ }^{28}$, for which each time slice consists of 2000 years representative of a certain average absolute global mean surface temperature value ('PD' for present-day, ' $2 \mathrm{C}$ ' for a $2{ }^{\circ} \mathrm{C}$ warming and ' $3 \mathrm{C}$ ' for a $3{ }^{\circ} \mathrm{C}$ warming, the latter two relative to pre-industrial climate $)^{27}$. Furthermore, we use six transient large ensemble model simulations collected by the US CLIVAR Working Group on Large Ensemble ${ }^{26}$ (available at: http://www.cesm.ucar.edu/projects/community-projects/MMLEA/). These simulations cover the period 1950-2100 and are carried out using six different climate models ${ }^{28,46-50}$, the number of ensemble members ranges from 16 to 50: CanESM2 (50 members), CESM1-CAM5 (35; we limit the analysis to members $1-35$ out of 40 available members, because members $36-40$ are slightly warmer than the rest which could affect extreme event frequency, see also http://www.cesm.ucar.edu/ projects/community-projects/LENS/known-issues.html.), CSIRO-Mk3-6-0 (30), EC-Earth (16), GFDL-CM3 (20), GFDL-ESM2M (30). All six models were also part of the Coupled Model Intercomparison Project, phase 5 (CMIP5). The simulations used the historical forcing for the period 1950-2005, and the strong forcing scenario for the period 2006-2100, for which the total radiative forcings in the year 2100 equals $8.5 \mathrm{~W} \mathrm{~m}^{-251}$. We use monthly mean values of near-surface temperature (tas) and precipitation (pr) in all analyses.

For the time slice model simulations with EC-Earth, the mean state is computed using all 2000 model years assuming that there is no forced trend within a time slice. Extreme event thresholds were defined based on the PD ensemble, and PRvalues were consequently computed based on threshold exceedances in the $2 \mathrm{C}$ and $3 \mathrm{C}$ time slice simulations. For the transient model experiments (US CLIVAR) we employ a 4th order polynomial to estimate the trend in the mean state, following the approach in related studies ${ }^{13,52}$. These time series were analysed by taking subsequent 30-year periods, with the period 1950-1979 being the reference period for defining extreme event thresholds. Confidence intervals were estimated by means of bootstrap resampling $(N=10,000)$. For our regional analysis we use the 26 IPCC SREX regions ${ }^{1,38}$, we only consider land cells within these regions. The global mean analysis takes into account both land and ocean cells.

\section{Data availability}

The model output for the EC-Earth time slice experiments is available on reasonable request from the corresponding author. The model output for the US CLIVAR large ensemble experiments were obtained from: http://www.cesm.ucar.edu/projects/ community-projects/MMLEA/.

\section{Code availability}

Code for data analysis is available on request from the corresponding author.

Received: 9 September 2020; Accepted: 24 November 2020; Published online: 04 January 2021

\section{References}

1. Field, C. B., Barros, V., Stocker, T. F. \& Dahe, Q. Managing the risks of extreme events and disasters to advance climate change adaptation: special report of the intergovernmental panel on climate change (Cambridge University Press, 2012). 
2. Herring, S. C. et al. Explaining extreme events of 2016 from a climate perspective. Bull. Am. Meteorol. Soc. 99, S1-S157 (2018).

3. Herring, S. C., Christidis, N., Hoell, A., Hoerling, M. P. \& Stott, P. A. Explaining extreme events of 2017 from a climate perspective. Bull. Am. Meteorol. Soc. 99, S1-S117 (2019).

4. Herring, S. C., Christidis, N., Hoell, A., Hoerling, M. P. \& Stott, P. A. Explaining extreme events of 2018 from a climate perspective. Bull. Am. Meteorol. Soc. 101, S1-S140 (2020).

5. Mora, C. et al. Global risk of deadly heat. Nat. Climate Change 7, 501-506 (2017).

6. De Bono, A., Peduzzi, P., Kluser, S. \& Giuliani, G. Impacts of summer 2003 heat wave in europe. Tech. Rep., United Nations Environment Programme. https://archive-ouverte.unige.ch/unige:32255 (2004).

7. Jonkman, S. N., Godfroy, M., Sebastian, A. \& Kolen, B. Brief communication: loss of life due to hurricane harvey. Nat. Hazards Earth Syst. Sci. 18, 1073-1078 (2018).

8. Sebastian, A., Gori, A., Blessing, R. B., van der Wiel, K. \& Bass, B. Disentangling the impacts of human and environmental change on catchment response during hurricane harvey. Environ. Res. Lett. 14, 124023 (2019).

9. Frame, D. J., Wehner, M. F., Noy, I. \& Rosier, S. M. The economic costs of hurricane harvey attributable to climate change. Climatic Change 160, 271-281 (2020).

10. Schaeffer, M., Selten, F. \& Opsteegh, J. Shifts of means are not a proxy for changes in extreme winter temperatures in climate projections. Climate Dyn. 25, 51-63 (2005).

11. Stouffer, R. \& Wetherald, R. Changes of variability in response to increasing greenhouse gases. part i: Temperature. J. Climate 20, 5455-5467 (2007).

12. Donat, M. G. \& Alexander, L. V. The shifting probability distribution of global daytime and night-time temperatures. Geophys. Res. Lett. 39, L14707 (2012).

13. Lewis, S. C. \& King, A. D. Evolution of mean, variance and extremes in 21 st century temperatures. Weather Climate Extremes 15, 1-10 (2017).

14. Pendergrass, A. G., Knutti, R., Lehner, F., Deser, C. \& Sanderson, B. M. Precipitation variability increases in a warmer climate. Sci. Rep. 7, 1-9 (2017).

15. Lenderink, G. \& Van Meijgaard, E. Increase in hourly precipitation extremes beyond expectations from temperature changes. Nat. Geosci. 1, 511-514 (2008).

16. Brown, P. T., Ming, Y., Li, W. \& Hill, S. A. Change in the magnitude and mechanisms of global temperature variability with warming. Nat. Climate Change 7, 743-748 (2017).

17. Bintanja, R. et al. Strong future increases in Arctic precipitation variability linked to poleward moisture transport. Sci. Adv. 6, eaax6869 (2020).

18. Box, J. E. et al. Key indicators of Arctic climate change: 1971-2017. Environ. Res. Lett. 14, 045010 (2019).

19. Pithan, F. \& Mauritsen, T. Arctic amplification dominated by temperature feedbacks in contemporary climate models. Nat. Geosci. 7, 181-184 (2014).

20. Screen, J. A. \& Simmonds, I. The central role of diminishing sea ice in recent arctic temperature amplification. Nature 464, 1334-1337 (2010).

21. Boer, G. Changes in interannual variability and decadal potential predictability under global warming. J. Climate 22, 3098-3109 (2009).

22. Reusen, J., van der Linden, E. \& Bintanja, R. Differences between arctic interannual and decadal variability across climate states. J. Climate 32, 6035-6050 (2019).

23. Bintanja, R. \& Selten, F. Future increases in Arctic precipitation linked to local evaporation and sea-ice retreat. Nature 509, 479-482 (2014).

24. Fischer, E. M. \& Knutti, R. Anthropogenic contribution to global occurrence of heavy-precipitation and high-temperature extremes. Nat. Climate Change 5, 560-564 (2015).

25. Stott, P. A., Stone, D. A. \& Allen, M. R. Human contribution to the european heatwave of 2003. Nature 432, 610-614 (2004).

26. Deser, C. et al. Insights from Earth system model initial-condition large ensembles and future prospects. Nat. Climate Change 10, 277-286 (2020).

27. Van der Wiel, K., Wanders, N., Selten, F. \& Bierkens, M. Added value of large ensemble simulations for assessing extreme river discharge in a $2{ }^{\circ} \mathrm{C}$ warmer world. Geophys. Res. Lett. 46, 2093-2102 (2019).

28. Hazeleger, W. et al. EC-Earth v2.2: description and validation of a new seamless earth system prediction model. Climate Dyn. 39, 2611-2629 (2012).

29. Lau, N.-C. \& Nath, M. J. A model study of heat waves over north america: Meteorological aspects and projections for the twenty-first century. J. Climate 25, 4761-4784 (2012).

30. Lau, N.-C. \& Nath, M. J. Model simulation and projection of european heat waves in present-day and future climates. J. Climate 27, 3713-3730 (2014).

31. Argüeso, D., Di Luca, A., Perkins-Kirkpatrick, S. E. \& Evans, J. P. Seasonal mean temperature changes control future heat waves. Geophys. Res. Lett. 43, 7653-7660 (2016).
32. Di Luca, A., de Elía, R., Bador, M. \& Argüeso, D. Contribution of mean climate to hot temperature extremes for present and future climates. Weather Climate Extremes 28, 100255 (2020).

33. LaJoie, E. \& DelSole, T. Changes in internal variability due to anthropogenic forcing: a new field significance test. J. Climate 29, 5547-5560 (2016).

34. Lochbihler, K., Lenderink, G. \& Siebesma, A. P. Response of extreme precipitating cell structures to atmospheric warming. J. Geophys. Res. Atmos. 124, 6904-6918 (2019).

35. Arnell, N. W., Lowe, J. A., Lloyd-Hughes, B. \& Osborn, T. J. The impacts avoided with a $1.5 \mathrm{c}$ climate target: a global and regional assessment. Climatic Change 147, 61-76 (2018).

36. King, A. D., Karoly, D. J. \& Henley, B. J. Australian climate extremes at $1.5 \mathrm{c}$ and $2 \mathrm{c}$ of global warming. Nat. Climate Change 7, 412-416 (2017).

37. King, A. D. \& Karoly, D. J. Climate extremes in Europe at 1.5 and 2 degrees of global warming. Environ. Res. Lett. 12, 114031 (2017).

38. Seneviratne, S. et al. Notes and technical details on chapter 3 figures. In Managing the risks of extreme events and disasters to advance climate change adaptation: Special report of the Intergovernmental Panel on Climate Change, chap. 3 (eds Field, C. B., Barros, V., Stocker, T. F. \& Dahe, Q.) (Cambridge University Press, 2012).

39. Donat, M. G., Pitman, A. J. \& Seneviratne, S. I. Regional warming of hot extremes accelerated by surface energy fluxes. Geophys. Res. Lett. 44, 7011-7019 (2017).

40. Warner, M. D., Mass, C. F. \& Salathé Jr, E. P. Changes in winter atmospheric rivers along the North American west coast in CMIP5 climate models. J. Hydrometeorol. 16, 118-128 (2015).

41. Randall, D. A. et al. Climate models and their evaluation. In Climate change 2007: The physical science basis. Contribution of Working Group I to the Fourth Assessment Report of the IPCC (FAR), 589-662 (Cambridge University Press, 2007)

42. Giorgi, F. \& Lionello, P. Climate change projections for the Mediterranean region. Glob. Planet. Change 63, 90-104 (2008).

43. Philandras, C. et al. Long term precipitation trends and variability within the Mediterranean region. Nat. Hazards Earth System Sci. 11, 3235 (2011).

44. Zappa, G., Hawcroft, M. K., Shaffrey, L., Black, E. \& Brayshaw, D. J. Extratropical cyclones and the projected decline of winter Mediterranean precipitation in the CMIP5 models. Clim. Dyn. 45, 1727-1738 (2015).

45. Zappa, G., Hoskins, B. J. \& Shepherd, T. G. The dependence of wintertime mediterranean precipitation on the atmospheric circulation response to climate change. Environ. Res. Lett. 10, 104012 (2015).

46. Jeffrey, S. et al. Australia's CMIP5 submission using the CSIRO-Mk3. 6 model. Aust. Meteor. Oceanogr. J 63, 1-13 (2013).

47. Kay, J. E. et al. The community earth system model (cesm) large ensemble project: a community resource for studying climate change in the presence of internal climate variability. Bull. Am. Meteorol. Soc. 96, 1333-1349 (2015).

48. Rodgers, K. B., Lin, J. \& Frölicher, T. L. Emergence of multiple ocean ecosystem drivers in a large ensemble suite with an earth system model. Biogeosciences 12, 3301-3320 (2015)

49. Kirchmeier-Young, M. C., Zwiers, F. W. \& Gillett, N. P. Attribution of extreme events in Arctic sea ice extent. J. Climate 30, 553-571 (2017).

50. Sun, L., Alexander, M. \& Deser, C. Evolution of the global coupled climate response to Arctic sea ice loss during 1990-2090 and its contribution to climate change. J. Climate 31, 7823-7843 (2018).

51. Van Vuuren, D. P. et al. The representative concentration pathways: an overview. Climatic Change 109, 5 (2011).

52. Vinnikov, K. Y. \& Robock, A. Trends in moments of climatic indices. Geophys. Res. Lett. 29, 14-1 (2002).

\section{Acknowledgements}

The authors thank the individual modelling groups for their efforts in producing the transient large ensembles experiments, and the US CLIVAR Working Group on Large Ensembles for collecting and making available the ensemble data. We are grateful to the EC-Earth consortium for their contribution to the development of the Earth System Model EC-Earth. Acknowledgment is made for the use of ECMWF's computing and archive facilities in this research. We thank Peter Pfleiderer for sharing the code to produce Fig. 4 and all similar figures. This work is part of the HiWAVES3 project, for which funding was supplied by the Netherlands Organisation of Scientific Research (NWO) under Grant Number ALWCL.2 016.2. HiWAVES3 was funded under a joint JPI Climate-Belmont Forum call (2015).

\section{Author contributions}

K.W. and R.B. contributed to the design of the study, the interpretation of the results and commented on the manuscript. K.W. performed the EC-Earth time slice model simulations, analysed the data, and wrote the manuscript. 


\section{Competing interests}

The authors declare no competing interests.

\section{Additional information}

Supplementary information is available for this paper at https://doi.org/10.1038/s43247020-00077-4

Correspondence and requests for materials should be addressed to K.v.d.W.

Peer review information Primary handling editor: Heike Langenberg.

Reprints and permission information is available at http://www.nature.com/reprints

Publisher's note Springer Nature remains neutral with regard to jurisdictional claims in published maps and institutional affiliations. (c) (i) Open Access This article is licensed under a Creative Commons Attribution 4.0 International License, which permits use, sharing, adaptation, distribution and reproduction in any medium or format, as long as you give appropriate credit to the original author(s) and the source, provide a link to the Creative Commons license, and indicate if changes were made. The images or other third party material in this article are included in the article's Creative Commons license, unless indicated otherwise in a credit line to the material. If material is not included in the article's Creative Commons license and your intended use is not permitted by statutory regulation or exceeds the permitted use, you will need to obtain permission directly from the copyright holder. To view a copy of this license, visit http://creativecommons.org/ licenses/by/4.0/.

(C) The Author(s) 2021 